\title{
GAMBARAN PERAN SUAMI DALAM PEMILIHAN ALAT KONTRASEPSI DI PMB BIDAN ELIS YANTI S KABUPATEN TASIKMALAYA
}

\section{DESCRIPTION OF THE HUSBAND'S ROLE IN THE SELECTION OF CONTRACEPTIVE EQUIPMENT IN PMB MIDWIFE ELIS YANTI S, TASIKMALAYA REGENCY}

\author{
Nurjannah Adawiyah ${ }^{1^{*}}$, Siti Rohmah ${ }^{2}$ \\ ${ }^{1,2}$ Program Studi D-III Kebidanan, Fakultas Ilmu Kesehatan, Universitas Galuh \\ Jalan R.E Martadinata No.10 Ciamis 46213, Indonesia \\ *E-mail corresponding: nurjannahadawiyah24@gmail.com \\ (Diterima: Maret 2021; disetujui April 2021; dipublish Mei 2021)
}

\begin{abstract}
ABSTRAK
Praktek Mandiri Bidan sangat berperan dalam pelayanan kontrasepsi, PUS lebih banyak konsultasi KB di PMB dibandingkan ke fasilitas kesehatan lainnya. Keterlibatan suami sangat penting dalam mendukung program $\mathrm{KB}$, namun kenyataannya banyak suami yang tidak mendampingi istri saat memilih kontrasepsi. Tujuan penelitian ini untuk mengetahui gambaran peran suami dalam pemilihan alat kontrasepsi. Jenis penelitian ini termasuk penelitian deskriptif dengan populasi pasangan usia subur yang sudah menjadi akseptor KB hormonal dan non hormonal di PMB bidan Elis Yanti S Kabupaten Tasikmalaya pada 3 bulan terakhir mencapai 107 orang, teknik sampling secara random yaitu 52 Responden. Hasil penelitian menunjukkan peran suami dalam pemilihan alat kontrasepsi di PMB bidan Elis Yanti S Kabupaten Tasikmalaya dapat disimpulkan bahwa dalam pemilihan alat kontrasepsi di PMB bidan Elis Yanti S Kabupaten Tasikmalaya lebih dari setengahnya suami memiliki peran yang cukup yaitu 29 orang $(55,8 \%)$. Agar suami terlibat atau berperan dalam pengambilan keputusan maka salah satu caranya adalah dengan memberikan penyuluhan seperti konseling tentang pentingnya $\mathrm{KB}$, macam macam $\mathrm{KB}$, dampak serta efek kedepannya yang merupakan solusi yang tepat untuk meningkatkan peran serta dukungan suami terhadap pengambilan keputusan istri dalam ber-KB. Peneliti selanjutnya diharapkan menganalisis faktor yang berhubungan dengan peran suami dalam pendampingan istri
\end{abstract}

Kata kunci: Peran, Suami, Keluarga Berencana

\begin{abstract}
The practice of Mandiri Midwife plays a role in contraceptive services, PUS has more kb consultations in PMB than to other health facilities. Husband's involvement is very important in supporting $\mathrm{kb}$ program. The purpose of this study is to find out the picture of the role of husbands in the selection of contraceptives. This type of research includes descriptive research with a population of couples of childbearing age who have become hormonal and non-hormonal $\mathrm{kb}$ acceptors in PMB midwife Elis Yanti S Tasikmalaya district in the last 3 months reached 107 people, random sampling techniques that are 52 Respondents. The results showed the role of husbands in the selection of contraceptives in PMB midwives Elis Yanti S Tasikmalaya district can be concluded that in the selection of contraceptives in PMB midwives Elis Yanti S Tasikmalaya more than half of husbands have a sufficient role that is 29 people $(55.8 \%)$. In order for the husband to be involved or play a role in decision making, one way is to provide counseling such as counseling about the importance of birth control, various kinds of birth control, the impact and effect of the future which is the right solution to increase the role and support of the husband to the wife's decision making in $\mathrm{kb}$.
\end{abstract}

Keywords: role, Husband, Family Planning 


\section{PENDAHULUAN}

Indonesia merupakan salah satu negara berkembang dengan berbagai jenis masalah, salah satunya yaitu dibidang kependudukan. Badan Pusat Statistik (BPS) sudah merilis sensus penduduk 2020. Berdasarkan paparan BPS, jumlah penduduk Indonesia per September 2020 bertambah 32,57 juta jiwa dari sepuluh tahun lalu menjadi 270,2 juta jiwa. Di tahun 2010, jumlah penduduk Indonesia masih 237,63 juta jiwa. Ini artinya selama tahun 2010 sampai 2020, laju pertumbuhan penduduk Indonesia sebesar $1,25 \%$. Jumlah penduduk laki-laki hasil sensus penduduk Indonesia 2020 adalah sebanyak 136,66 juta jiwa atau sekitar $50,58 \%$ dari total penduduk, dan jumlah penduduk perempuan sebesar 49,42\% dengan jumlah 133,54 juta jiwa. Angka tersebut merupakan hasil perhitungan yang dilakukan oleh Pusat Data dan Informasi Kementerian Kesehatan dengan bimbingan dari Badan Pusat Statistik (BPS), dengan menggunakan metode geometrik. Pulau Jawa merupakan wilayah yang memiliki populasi penduduk Indonesia paling banyak. Logika secara umum digunakan sebagai landasan kebijakan untuk mengendalikan laju pertumbuhan penduduk dan secara khusus hal ini juga digunakan untuk memberikan penekanan mengenai pentingnya suatu keluarga melakukan pengaturan pembatasan jumlah anak (BPS, 2019).

Jawa Barat merupakan salah satu provinsi penyumbang terbesar jumlah penduduk di Indonesia kurang lebih 49.316.712 pada tahun 2019 dengan kepadatan penduduk sebesar 1.219 orang $/ \mathrm{km}$, dengan luas wilayah sebesar 37.173,97 km2 (BPS, 2014). Sedangkan laju pertumbuhan penduduk (LPP) Jawa Barat berdasarkan Sensus Penduduk tahun 2019 (SP 2019) adalah $1,90 \%$ per tahun. Kontribusi LPP di Jawa Barat berasal dari 3 komponen utama yaitu migrasi, fertilitas, dan mortalitas (Dinkes Jabar, 2020).

Kabupaten Tasikmalaya menduduki peringkat keenam dengan jumlah penduduk terbanyak di Kabupaten yang ada di Jawa Barat yaitu sekitar 1,7 juta jiwa (Profil Keluarga Kabupaten 2019). Data Dinas Kependudukan dan KB Kabupaten Tasikmalaya (2020) menunjukkan Jumlah Pasangan Usia Subur di Kabupaten Tasikmalaya sebanyak 227.450 dan Peserta KB Aktif sebanyak 19,26\% dengan penggunaan alat kontrasepsi IUD sebanyak 2.763, MOW sebanyak 604, MOP sebanyak 61 , kondom sebanyak 60, implant sebanyak 2.427 dan suntik sebanyak 15.152, serta PIL sebanyak 7.246.

Praktek Mandiri Bidan sangat berperan dalam pelayanan kontrasepsi, PUS lebih banyak konsultasi KB di PMB dibandingkan ke fasilitas kesehatan lainnya. Salah satu PMB yang ada di Kecamatan Sukarame adalah PMB Elis Yanti Susanti. Berdasarkan data dari PMB Bidan Elis Yanti Susanti Sukarame Kabupaten Tasikmalaya menunjukkan terjadi penurunan dalam penggunaan kontrasepsi yaitu pada tahun 2020 sebanyak 306 orang dengan jenis alat kontrasepsi Suntik KB sebanyak 297 orang Pil KB sebanyak 6 orang dan IUD sebanyak 3 orang, sedangkan tahun 2019 sebanyak 385 orang dengan jenis alat kontrasepsi Suntik 
KB sebanyak 369 orang Pil KB sebanyak 12 orang dan IUD sebanyak 4 orang. Penurunan penggunaan kontrasepsi tersebut dapat disebabkan oleh keputusan PUS dalam memilih alat kontrasepsi. Penggunaan kontrasepsi merupakan tanggung jawab bersama antara pria dan wanita sebagai pasangan, sehingga metode kontrasepsi yang akan dipilih sesuai dengan kebutuhan serta keinginan bersama. Peran suami sebagai kepala keluarga sangat penting dalam penggunaan kontrasepsi. Suami dapat memutuskan penggunaan kontrasepsi bagi istrinya (Saefudin, 2012).

Penggunaan alat kontrasepsi oleh pasangan usia subur didasari oleh banyak faktor diantaranya faktor kesehatan, tingkat pengetahuan tentang kontrasepsi dan dukungan dari suami (Nasution, 2011). Faktor - faktor yang juga akan mempengaruhi keberhasilan program $\mathrm{KB}$ adalah hak pasangan suami istri untuk menentukan dan memutuskan alat kotrasepsi yang akan digunakan dan pilihan untuk menentukan kapan hamil, melahirkan dan menghentikan KB. (Hartono H, 2013) mengatakan bahwa factor dukungan suami memegang peranan penting karena suami merupakan kepala rumah tangga dan pengambilan keputusan dalam rumah tangga dilakukan oleh suami termasuk pengambilan keputusan untuk jenis alat kontrasepsi yang digunakan.

Wanita harus menentukan jenis metode kontrasepsi dengan tepat sesuai kondisi dan kebutuhan. Wanita/ibu harus memperhatikan beberapa faktor dalam memilih suatu metode kontrasepsi, seperti status kesehatan, efek samping potensial metode kontrasepsi, konsekuensi terhadap kehamilan yang tidak diinginkan, banyaknya anak dalam keluarga yang diinginkan, kerjasama pasangan, dan norma budaya serta agama mengenai kemampuan mempunyai anak. Pemilihan jenis alat kontrasepsi diperlukan pemikiran yang matang antara suami maupun istri karena mereka yang menanggung konsekuensi maupun efek samping dalam melakukan KB (Hanafi, 2016).

Peran suami dalam KB bisa diwujudkan secara langsung maupun tidak langsung. Partisipasi secara langsung dapat diwujudkan dengan menjadi akseptor KB dan partisipasi suami secara tidak langsung adalah mendukung istri dalam ber-KB yaitu, sebagai motivator dan pengambil keputusan bersama, guna merencanakan jumlah anak dalam keluarga. Peran suami sebagai motivator dengan memberikan motivasi/dorongan untuk menjadi peserta $\mathrm{KB}$ dengan menggunakan salah satu jenis alat kontrasepsi (Rafidah, 2014). Pemilihan alat kontrasepsi sangat berhubungan dengan dukungan suami atau persetujuan pasangan (Bernadus, Agnes M, \& Gresty M, 2013). Dukungan yang diberikan oleh suami untuk memantapkan pemakaian kontrasepsi pada istri dan bahkan istri merasa tenang menjadi peserta KB apabila suaminya memberikan dukungan penuh, termasuk menemani saat konseling, pemasangan alat kontrasepsi, menemani control dan selalu mengayomi istri 
saat sesuatu yang tidak diinginkan terjadi (Faridah, 2014).

Hasil penelitian Julfainda (2018) menunjukkan bahwa lebih dari setengah suami tidak berperan dalam pemilihan jenis alat kontrasepsi pada ibu dengan presentase $54.3 \%$ dan $45.7 \%$. Penelitian Rahmawati (2019) menyimpulkan bahwa peran suami sebagai motivator dalam pengambilan keputusan Keluarga Berencana sebagian besar adalah baik, peran suami sebagai edukator dalam pengambilan keputusan Keluarga Berencana sebagian besar adalah kurang baik, dan peran suami sebagai fasilitator dalam pengambilan keputusan Keluarga Berencana sebagian besar adalah baik.

Hasil wawancara dengan $10 \mathrm{ibu}$ akseptor KB tentang peran suami terhadap pemilihan alat kontrasepsi diperoleh data awal bahwa 7 ibu mengatakan suami tidak pernah mengantar istri untuk melakukan KB maupun mengantar konsultasi memilih $\mathrm{KB}$ yang sesuai karena suami berasumsi bahwa penggunaan alat kontraspsi itu tanggung jawab wanita, 3 ibu mengatakan keputusan pemilihan kontrasepsi sudah dirundingkan di rumah, suami mendukung tetapi suami sibuk untuk bekerja. Suami bersikap acuh dalam pemilihan KB dan menyerahkan keputusan kepada istri. Peran suami dalam keluarga sangatlah penting terutama dalam mendukung dan mengambil keputusan dalam program KB. Berdasarkan hal tersebut penulis tertarik untuk melakukan penelitian tentang Gambaran peran suami dalam pemilihan alat kontrasepsi di PMB bidan Elis Yanti S Kabupaten Tasikmalaya.

\section{METODE PENELITIAN}

Jenis penelitian ini termasuk penelitian deskriptif. Populasi pada penelitian ini adalah pasangan usia subur yang sudah menjadi akseptor KB hormonal dan non hormonal di PMB bidan Elis Yanti S Kabupaten Tasikmalaya pada 3 bulan terakhir mencapai 107 orang. Tekhnik penentuan sampel dalam penelitian ini menggunakan teknik accidental sampling. Penelitian akan dilakukan di Praktek Mandiri Bidan Elis Yanti Susanti Sukarame, Tasikmalaya.

\section{HASIL DAN PEMBAHASAN}

\section{Hasil Penelitian}

Tabel 1

Distribusi Frekuensi Peran Suami sebagai Motivator Dalam Pemilihan Alat Kontrasepsi Di PMB Bidan Elis Yanti S Kabupaten Tasikmalaya

\begin{tabular}{lcc} 
Motivator & f & \% \\
\hline Baik & 13 & 25.0 \\
Cukup & 29 & 55.8 \\
Kurang & 10 & 19.2 \\
\hline Total & $\mathbf{5 2}$ & $\mathbf{1 0 0}$
\end{tabular}

Sumber: Data Primer Hasil Penelitian 2021

Data pada tabel 1 menunjukkan bahwa dalam pemilihan alat kontrasepsi di PMB bidan Elis Yanti S Kabupaten Tasikmalaya sebagian besar suami memiliki peran sebagai motivator yang cukup yaitu 29 orang $(55,8 \%)$, dan sebagian kecil suami memiliki peran yang kurang yaitu 10 orang $(19,2 \%)$ dan yang baik yaitu 12 orang $(25 \%)$. 


\section{Peran Suami Sebagai Edukator}

Tabel 2

Distribusi Frekuensi Peran Suami sebagai Edukator Dalam Pemilihan Alat Kontrasepsi Di PMB Bidan Elis Yanti S Kabupaten Tasikmalaya

\begin{tabular}{lcc} 
Edukator & F & $\mathbf{\%}$ \\
\hline Baik & 6 & 11.5 \\
Cukup & 20 & 38.5 \\
Kurang & 26 & 50.0 \\
\hline Total & $\mathbf{5 2}$ & $\mathbf{1 0 0}$ \\
Sumber: Data Primer & Hasil Penelitian 2021
\end{tabular}

Data pada tabel 2 menunjukkan bahwa dalam pemilihan alat kontrasepsi di PMB bidan Elis Yanti S Kabupaten Tasikmalaya hampir setengah suami memiliki peran sebagai educator yang cukup yaitu 20 orang $(38,5 \%)$, setengah dari suami memiliki peran kurang (50\%) dan sebagian kecil suami memiliki peran yang baik yaitu 6 orang $(11,5 \%)$

\section{Peran Suami Sebagai Fasilitator}

Tabel 3

Distribusi Frekuensi Peran Suami sebagai Fasilitator Dalam Pemilihan Alat Kontrasepsi Di PMB Bidan Elis Yanti S Kabupaten Tasikmalaya

\begin{tabular}{lcc} 
Fasilitator & f & \% \\
\hline Baik & 11 & 21.1 \\
Cukup & 38 & 73.0 \\
Kurang & 3 & 05.7 \\
\hline Total & $\mathbf{5 2}$ & $\mathbf{1 0 0}$
\end{tabular}

Sumber: Data Primer Hasil Penelitian 2021

Data pada tabel 3 menunjukkan bahwa dalam pemilihan alat kontrasepsi di PMB bidan Elis Yanti S Kabupaten Tasikmalaya hampir setengah suami memiliki peran sebagai fasilitatoror yang cukup yaitu 38 orang $(73.0 \%)$, setengah dari suami memiliki peran baik yaitu (21.1\%) dan sebagian kecil suami memiliki peran yang kurang yaitu 3 orang $(0.57 \%)$.

\section{Pembahasan}

Hasil penelitian diperoleh gambaran bahwa dalam pemilihan alat kontrasepsi di PMB bidan Elis Yanti $S$ Kabupaten Tasikmalaya sebagian besar suami memiliki peran yang cukup yaitu 29 orang $(55,8 \%)$. Peran suami dalam pemilihan alat kontrasepsi yang baru mencapai kategori cukup dapat disebabkan oleh beberapa faktor diantaranya pendidikan, pengalaman, jumlah anak, pekerjaan, budaya, status perkawinan, dan status sosial ekonomi. Pada wilayah bidan Elis Yanti S Kabupaten Tasikmalaya secara garis besar merupakan wilayah perdesaan sehingga penduduknya sebagian besar berpendidikan dasar dan menengah mempunyai pendapatan yang masih dibawah upah minimum regional.

Peran suami dalam pemilihan alat kontrasespsi KB menunjukkan bahwa suami cukup berperan sebagai motivator, dan fasilitator. Faktor yang berhubungan dengan peran suami sebagai motivator yang cukup baik dalam pengambilan keputusan keluarga berencana diantaranya adalah faktor usia suami. Karakteristik suami menurut umur menunjukkan bahwa sebagian besar suami berada dalam usia dewasa awal yang memiliki karakteristik sabar dan memahami orang lain (Jahya, 2011). Sikap suami yang sabar dan memahami orang lain dapat membuat istri merasakan adanya perhatian dan dukungan dari suami. Adanya motivasi yang kuat menimbulkan keyakinan pemilihan kontrasepsi yang dilakukan oleh istri tepat dan sesuai dengan kebutuhan (Vadnjal and Vadnjal, 2013). 
Peran suami sebagai fasilitator dalam pengambilan keputusan keluarga berencana termasuk cukup baik. Peran suami sebagai fasilitator adalah membantu istri dalam memiliha dan menggunakan alat kontrasepsi seperti mengingatkan istri untuk melakukan kontrol atau mengingatkan istri untuk minum pil, dan mengantar istri ke fasilitas pelayanan kesehatan untuk kontrol (Suparyanto, 2011). Berdasarkan hasil penelitian menunjukkan bahwa peran suami perlu ditingkatkan kembali, karena pemilihan jenis alat kontrasepsi diperlukan pemikiran yang matang antara suami maupun istri karena mereka yang menanggung konsekuensi maupun efek samping dalam melakukan KB. Peran suami dalam KB bisa diwujudkan secara langsung maupun tidak langsung. Partisipasi secara langsung dapat diwujudkan dengan menjadi akseptor KB dan partisipasi suami secara tidak langsung adalah mendukung istri dalam ber-KB yaitu, sebagai motivator dan pengambil keputusan bersama, guna merencanakan jumlah anak dalam keluarga. Peran suami sebagai motivator dengan memberikan motivasi/dorongan untuk menjadi peserta KB dengan menggunakan salah satu jenis alat kontrasepsi.

\section{SIMPULAN}

Berdasarkan hasil penelitian di PMB Elis Yanti Susanti Kabupaten Tasikmalaya tentang gambaran peran suami dalam pemilihan alat kontrasepsi di PMB bidan Elis Yanti S Kabupaten Tasikmalaya hampir setengah suami memiliki peran sebagai fasilitatoror yang cukup yaitu 38 orang $(73.0 \%)$

\section{DAFTAR PUSTAKA}

Bernadus J D, Agnes M, Gresty M. (2013). Faktor-Faktor Yang Berhubungan dengan Pemilihan Alat Kontrasepsi Dalam Rahim (AKDR) Bagi Akseptor KB Di Puskesmas Jailalolo. Jurnal Keperawatan, Vol.1, No.1, Agustus 2013: Manado

Rahmawati Sari, D (2019). Hubungan Pengetahuan dan Sikap Pria Tentang Keluarga Berencana dengan Perilaku Pria dalam Berpartisipasi Menggunakan Metode Kontrasepsi Keluarga Berencana di desa Larangan

Kecamatan Larangan Kabupaten Brebes. Jurnal GASTER, Vol. 8, No. 1 Februari 2011: 633-646

Suparyanto (2011). Konsep Suami dalam Keluarga Berencana. Jakarta: Salemba Medika 